\title{
HYDRATION AND ACETYLATION OF LIMONENE. SUPPORTED HETEROPOLYACIDS
}

\author{
MARIA CECILIA AVILA, NORA A. COMELLI, NORBERTO H. FIRPO ${ }^{a}$, \\ ESTHER N. PONZI ${ }^{a}$, MARTA I. PONZI* \\ INTEQUI (CONICET- UNSL) 25 de Mayo 384. V. Mercedes, San Luis. Argentina \\ ${ }^{a}$ CINDECA (CONICET-UNLP) Calle $47 N^{\circ}$ 257. La Plata, Buenos Aires. Argentina. \\ Agencia Nacional de Promoción Científica Tecnológica y de Innovación. Av. Córdoba 831. Buenos Aires. Argentina. \\ (Received: 28 May 2007 - Accepted: 11 January 2008)
}

\begin{abstract}
The limonene hydration and acetylation in liquid phase catalyzed by phosphotungstic and phosphomolybdic acid bulk and supported on silica and titanium dioxide were studied.

The reaction was performed in a batch reactor in acetic acid at $40^{\circ} \mathrm{C}$, with magnetic stirring of the reaction mixture. Reaction products were analyzed by gaseous chromatography with FID detector using a capillary column for separation of products. The identification of compounds was made with pattern terpenes and by gaseous chromatography with mass spectrometry.

All catalysts tested result to be active in the hydration and acetylation reaction of limonene. Catalysts based on phophotungstic acid (HPW) produce larger amount of hydration and acetylation products than phosphomolybdic acid (HPMo) catalyst. Hydration products increase faster than isomerization products when the reaction time is increased.

The structure of heteropolyacids and the presence of acid sites Brönsted and Lewis were determined by FTIR.
\end{abstract}

Keyword: Hydration, acetylation, limonene, heteropolyacids, $\alpha$-terpineol

\section{INTRODUCTION}

Alcohols and terpenic acetates produced by hydration and acetylation of limonene by acid catalysis are products of high value, which have many applications in pharmaceutical industry. Among alcohols, the most interesting is $\alpha$-terpineol $(1,2)$.

The $\alpha$-terpineol, monocyclic alcohol, is produced at industrial scale by hydration of $\alpha$-pinene with a mineral acid generating cis-terpene hydrate. The partial dehydration of cis-terpene leads to $\alpha$-terpineol. This is a complex process because the isomerization reaction of $\alpha$-pinene occurs simultaneously with hydration (3).

There exists an important amount of publications in which the hydration of $\alpha$-pinene and camphene is studied using different catalysts, molybdophosphoric acid immobilized in dense polymeric membranes (4), phosphotungstic acid (5) and polyvinylalcohol/molybdophosphoric acid (6). The number of publications related to hydration of limonene is limited. Robles et al. (7) have studied hydration and acetylation of limonene catalyzed by phosphotungstic acid.

Acid catalyzed hydration of limonene gives a complex mixture of monoterpenes and alcohols resulting from isomerization and hydration reactions. The selectivity to the desired products can be increased by controlling reaction variables (temperature, load of catalyst).

The limonene isomerization catalyzed by acid catalysts like sulfated zirconia and HPW on silica and titanium dioxide (8-9) was studied in our group.

The aim of this work is the study of the behavior of HPW $\left(\mathrm{H}_{3} \mathrm{PW}_{12} \mathrm{O}_{40}\right.$ $\left.\mathrm{nH}_{2} \mathrm{O}\right)$ and $\mathrm{HPMo}\left(\mathrm{H}_{3} \mathrm{PMo}_{12} \mathrm{O}_{40} \mathrm{nH}_{2} \mathrm{O}\right)$ catalysts, bulk and supported on titanium dioxide and silica in the hydration and acetylation reaction of limonene.

\section{EXPERIMENTAL}

Preparation of catalysts

Catalysts were prepared by impregnation of $\mathrm{TiO}_{2}$ and $\mathrm{SiO}_{2}$ (Aerosil 200) with phosphotungstic (HPW) or phosphomolybdic acid (HPMo). The impregnation was carried out in rotovapor at $100 \mathrm{rpm}$ and $350 \mathrm{mmHg}$ with the necessary amount of HPW or HPMo dissolved in an ethanol-water mixture to achieve the desired load of acid (40\% HPWSi), (50\% HPWTi), (25\% HPMoSi) and $(30 \% \mathrm{HPMoTi})$. The samples were dried for 12 hours and activated at $300^{\circ} \mathrm{C}$ for $4 \mathrm{~h}$.

Percentages are expressed as

$\%=$ active phase/(support+active phase) $\times 100$.

Test of catalytic activity

The catalytic activity was studied in a batch reactor with three openings; one is used to place a thermocouple, other for sample extraction with a micropipette and the third one, to place a refrigerant. The reaction is performed at constant temperature and magnetic stirring. For a standard reaction $3.2 \mathrm{ml}$ of limonene were added to $1.14 \mathrm{ml}$ glacial acetic acid, the mixture was heated up to $40^{\circ} \mathrm{C}$, when the temperature remained constant, the catalyst was added and the time began to be registered. The reaction was studied during $3 \mathrm{~h}$ and samples were extracted periodically and analyzed by chromatography.

Reaction products were analyzed by gaseous chromatography with FID detector and capillary column DB1 of $60 \mathrm{~m}$. A temperature program in the column was used from 75 up to $200^{\circ} \mathrm{C}$ at a rate of $3{ }^{\circ} \mathrm{C} / \mathrm{min}$. The identification of products was performed by comparison of retention times with pattern terpenes and confirmed with GC-MS.

\section{Characterization of catalysts}

Heteropolyacid structure was determined by infrared spectroscopy with Fourier transform using a Spectrum RX1 Perkin Elmer equipment. The spectrum was registered on pellets containing catalyst diluted in $\mathrm{KBr}$.

The type of sites present in the catalyst was determined by means of infrared spectroscopy, adsorbing pyridine on auto supported pellets. In order to prepare the pellet, $12 \mathrm{mg}$ catalyst are impregnated with $2 \mu 1$ pyridine, the pyridine is desorbed in air flow for 15 hours at $25^{\circ} \mathrm{C}$, and then, the auto supported pellet is prepared. Pyridine, when it is adsorbed on acid solids, can give three adsorption bands, one at $1536 \mathrm{~cm}^{-1}$ assigned to Brönsted acid sites, other at $1445 \mathrm{~cm}^{-1}$ corresponding to Lewis acid sites, and the third one at 1480 $\mathrm{cm}^{-1}$ corresponding to Brönsted acid sites as well as to Lewis acid sites.

\section{RESULTS AND DISCUSSION}

Characterization of catalysts

Keggin structure

Structure of catalysts HPW, HPWTi, HPWSi, HPMo, HPMoTi and HPMoSi was studied by FTIR. Bands observed for catalysts based on HPW are shown in Table I. The HPW and the HPWSi present signals like those reported in the literature assigned to the Keggin structure (10). The HPWTi catalyst shows signals at $1104,1058,966,894$ and $812 \mathrm{~cm}^{-1}$ reported for lacunar structure of the Keggin anion $\left[\mathrm{PW}_{11} \mathrm{O}_{39}\right]^{7-}$ whose signals correspond to $1100,1046,958,904,812$ and $742 \mathrm{~cm}^{-1}(11)$.

Table I. Frequency of bands assigned to catalysts based on HPW

\begin{tabular}{|c|c|c|c|}
\hline Assignment & HPW & WPWSi & HPWTi \\
\hline$v_{4}$ P-O & 1079 & 1081 & - \\
\hline$v_{3}$ W=O terminal & 987 & 981 & - \\
\hline$v_{2}$ O-W-O corner & 895 & 889 & 894 \\
\hline$v_{1}$ W-O-W axis & 802 & 798 & - \\
\hline
\end{tabular}

Bands observed for catalysts based on HPMo are shown in Table II. Murugan et al. (12) give the vibration frequency of signals for HPMo and also ranges among which they can be found, (760-800), (840-910), (960-1000) and 
(1060-1080). Table II shows that the three catalysts present bands within those limits, so we can suppose that destruction of Keggin structure did not exist when supporting HPMo in titanium dioxide or in silica.

\section{Acidity of catalysts}

FTIR spectra of adsorbed pyridine can be used to study the active sites in the catalyst. It is known that pyridine is adsorbed on Brönsted acid sites with characteristic bands at $1536 \mathrm{~cm}^{-1}$ and on Lewis acid sites with bands at 1445 $\mathrm{cm}^{-1}$. Results for catalysts HPWSi, HPWTi, HPMoSi and HPMoTi show bands at 1536 indicating the presence of Brönsted acid sites.

Table II Frequency of bands assigned to catalysts based on HPMo

\begin{tabular}{|c|c|c|c|}
\hline Assignment & HPMo & HPMoSi & HPMoTi \\
\hline$v_{4}$ P-O & 1066 & 1062 & 1068 \\
\hline$v_{3}$ Mo=O terminal & 969 & 973 & 962 \\
\hline$v_{2}$ Mo-O-Mo-O corner & 871 & 908 & 887 \\
\hline$v_{1}$ Mo-o-Mo axis & 787 & 799 & 770 \\
\hline
\end{tabular}

Catalytic activity

Transformation reaction of limonene begins with the exocyclic carbocation formation, which can be transformed into limonene isomers or react with water producing alcohols as it is shown in the scheme. Alcohols formed can react with acetic acid forming the corresponding acetates.

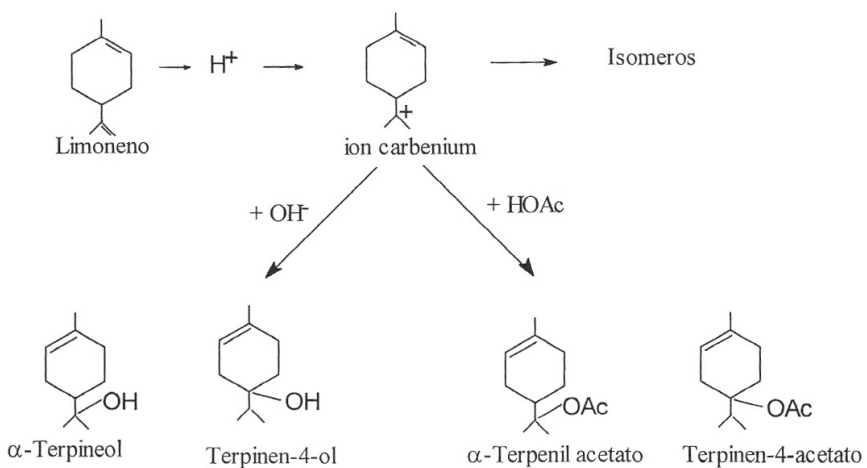

Scheme Reaction products

Results of experiments performed show a large variety of isomerization products, alcohols and acetates. Table III shows percentages of reaction products obtained from chromatograms after 1 hour reaction, where compounds are grouped according to the reaction type, isomerization products $\left(\mathrm{P}_{\text {isom }}\right)$, hydration products $\left(\mathrm{P}_{\text {hyd }}\right)$ and acetylation products $\left(\mathrm{P}_{\mathrm{Acet}}\right)$.

Products of interest are alcohols and acetates, while isomerization products are considered as by-products of this reaction and can be recycled for subsequent transformations.

Table III. Distribution of reaction products of hydration and acetylation of limonene

\begin{tabular}{|c|c|c|c|c|}
\hline Catalyst & $\% \mathrm{P}_{\text {isom }}$ & $\% \mathrm{P}_{\text {hyd }}$ & $\% \mathrm{P}_{\text {acet }}$ & $\mathrm{P}_{\text {hydd }+ \text { ace }} / \mathrm{P}_{\text {isom }}$ \\
\hline HPW & 2 & 2.3 & 4.7 & 3.5 \\
\hline HPWSi & 2.9 & 5.9 & 4.6 & 3.6 \\
\hline HPWTi & 3.1 & 5.8 & 4.8 & 3.4 \\
\hline HPMo & 4.7 & 2.1 & 5.5 & 1.6 \\
\hline HPMoSi & 2.8 & 1.9 & 3.1 & 1.8 \\
\hline HPMoTi & 3.5 & 4.9 & 3.2 & 2.3 \\
\hline
\end{tabular}

Reaction conditions: $40^{\circ} \mathrm{C}, 1 \mathrm{~h}$

HPMo catalyst produces the largest amount of isomers while HPW catalyst produces them in lower proportions. Supported catalysts based on HPW are the most useful for production of alcohols and acetates. The relation between products of interest (alcohols and acetates) with respect to by-products (isomerization) is higher for catalysts based on phosphotungstic acid.

Concentration of products as a function of time is shown in Figure 1 for the HPWSi catalyst. The concentration of hydration and acetylation products increases with time faster than isomerization products when the HPWSi catalyst is used; this does not occur with the HPMoSi catalyst. When the HPWSi catalyst is used, it is expected that prolonged reaction times would result in a selectivity increase toward desired products.

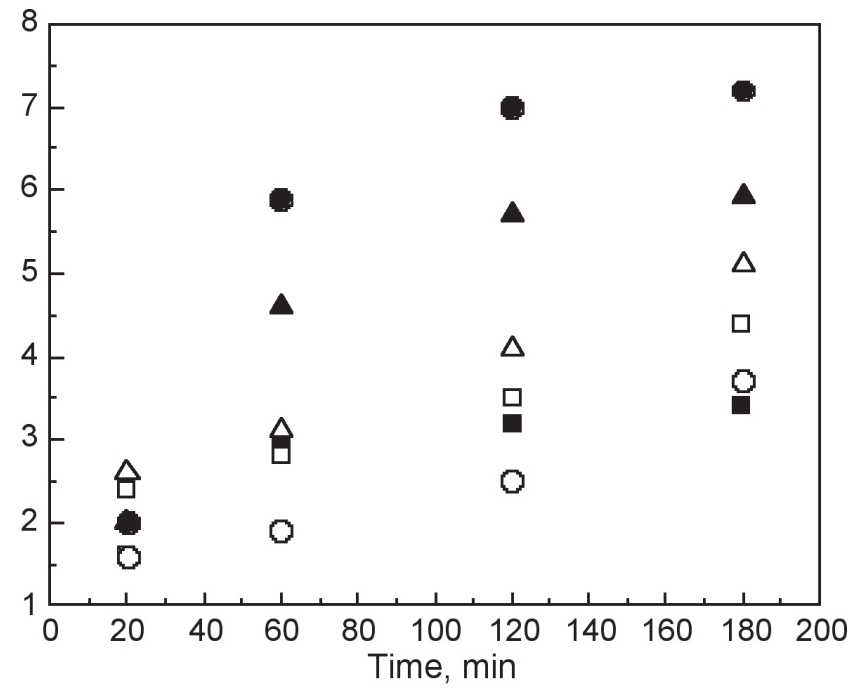

\section{Isomerization products Hydration products - Acetylation products}

Figure 1: Full symbols: HPWSi; empty symbols: HPMoSi

Activity can be expressed as limonene moles per weight unit of catalyst or as function of the catalyst active phase; from an industrial point of view it is more useful to express it per weight unit. Results obtained are shown in Table IV.

The catalytic activity expressed per unit of active phase is lower for the HPW catalyst with respect to the ones supported by the same acid, so it is possible to infer that the supported HPW favors carbocation formation, the same tendency is observed for the series of HPMo catalysts

Table IV: Activity of catalysts at 20 minutes

\begin{tabular}{|c|c|c|}
\hline Catalyst & Moles/h g(active phase) & Moles /h g(catalyst) \\
\hline HPW & 185 & 185 \\
\hline HPWSi & 694 & 278 \\
\hline HPWTi & 555 & 278 \\
\hline HPMo & 432 & 432 \\
\hline HPMoSi & 694 & 185 \\
\hline HPMoTi & 617 & 185 \\
\hline
\end{tabular}

\section{CONCLUSION}

All catalysts tested resulted to be active in the hydration and acetylation reaction of limonene.

Catalysts based on HPW produce larger amount of hydration and acetylation products than the ones obtained by using catalysts based on HPMo.

Isomerization and hydration products increase faster than isomerization products when the reaction time increases.

\section{ACKNOWLEDGEMENT}

Authors thank the financial support of UNSL, CONICET and ANPCyT. 


\section{REFERENCES}

1. J. H. van de Waal, J. van Bekkum, J. Vital, Mol. Catal. A: Chem. 105, 185, (1996).

2. H. Valente, J. Vital, in: H.U. Blase, A. Baiker, R. Prins (Eds.), Heterogeneous Catalysis and Fine Chemicals IV, Elsevier, Amsterdam, $555,(1997)$.

3. R.M. Traynor, R.M. Albert, R.L. Webb, in: D.F. Zinkel, J. Russels (Eds.), Naval Stores, Pulp Chemical Association, New York, 479, (1989).

4. J.E. Castanheiro, A.M. Ramos, I. Fonseca, J. Vital, Catal. Today 82, 187, (2003).

5. K. A. da Silva, I. V. Kozhevnikov, E. V. Gusevskaya, J. Mol. Catal. A Chem. 192, 129, (2003).

6. J.E. Castanheiro, I.M. Fonseca, A.M. Ramos, R. Oliveira, J. Vital. Catal. Today 104, 296, (2005).
7. P. A. Robles-Dutenhefner, K. A. da Silva, M. Rafiq, H. Siddiqui, I. V. Kozhevnikov, E. V. Gusevskaya, J. Mol. Catal. A: Chem., 175, 1-2, 33, (2001).

8. N. A. Comelli, E. N. Ponzi, M. I. Ponzi. Chem. Eng. J. 117 (2), 93, (2006).

9. N. A. Comelli, L. M. Grzona, O. Masini, E. N. Ponzi, M. I. Ponzi. XIX Simposio Iberoamericano de Catalisis Mexico (2004).

10. S. Patel, N. Purohit, A. Patel, J. Molec. Catal. A: Chemical 192, 195, (2003).

11. L.R. Pizzio, C.V. Cáseres, M.N. Blanco, Appl. Catal. A: General 167, 283, (1998).

12. A. Murugan, C. Kwon, G. Campet, B. Kale, Active and Passive Elec. Comp., Vol 26 (2), 81, (2003). 